\title{
Matrix metalloproteinase-2 C-1306T promoter polymorphism and breast cancer risk in the Saudi population
}

\author{
Hesham Mahmoud Saeed ${ }^{1,2 凶}$, Mohammad Saud Alanazi², Omair Alshahrani², \\ Narasimha Reddy Parine ${ }^{2}$, Huda Abdullah Alabdulkarim ${ }^{3}$ and Manal Aly Shalaby ${ }^{4}$
}

'Department of Bioscience and Technology, Institute of Graduate Studies and Research, Alexandria University, Alexandria, Egypt; ${ }^{2}$ Department of Biochemistry, College of Science, King Saud University, Riyadh, Kingdom of Saudi Arabia; ${ }^{3 T h e}$ Comprehensive Cancer Center at King Fahad Medical City, Riyadh, Kingdom of Saudi Arabia; ${ }^{4}$ Genetic Engineering and Biotechnology Research Institute (GEBRI), City for Scientific Research and Technology Applications, New Borg Alarab City, Alexandria, Egypt

\begin{abstract}
Matrix metalloproteinase-2 (MMP-2) is an enzyme with proteolytic activity against matrix proteins, particularly basement membrane constituents. A single nucleotide polymorphism (SNP) at -1306, which disrupts a Sp1-type promoter site (CCACC box), displayed a strikingly lower promoter activity with the T allele. In the present study, we investigate whether this MMP-2 SNP is associated with susceptibility to breast cancer in the Saudi population. Ninety breast cancer patients and 92 age matched controls were included in this study. TaqMan Allele Discrimination assay and DNA sequencing techniques were used for genotyping. The results showed that, the frequency of MMP-2 CC wild genotype was lower in breast cancer patients when compared with healthy controls ( 0.65 versus 0.79$)$. The homozygous $C C\left(O R=2, X^{2}=5.36\right.$, $\mathrm{p}=0.02)$ and heterozygous $\mathrm{CT}\left(\mathrm{OR}=1.98, \mathrm{X}^{2}=4.1, \mathrm{p}=0.04\right)$ showing significantly high risk of breast cancer in the investigated group. In conclusion our data suggest that the MMP-2 C-1306T polymorphism may be associated with increased breast cancer risk in the Saudi population.
\end{abstract}

Key words: breast cancer; matrix metalloproteinases; single nucleotide polymorphism; TaqMan Allele Discrimination assay

Received: 31 December, 2012; revised: 12 September, 2013; accepted: 13 September, 2013; available on-line: 18 September, 2013

\section{INTRODUCTION}

Breast cancer is one of the most common malignancies among women worldwide, in both developed and undeveloped countries. It is also leading cause of death in women in the 35-59 years age group (Strnad et al., 2007). The annual worldwide incidence of breast cancer is about 1.2 million (Cheema et al., 2008). One in nine women will suffer from breast carcinoma during her life and over 130 thousand women die from this disease each year (Tyczynski et al., 2002). Breast cancer is a leading malignancy among Saudi women comprising about $26 \%$ of all malignancies and is the foremost cause of cancer related death (Saudi Cancer Registry 2011). Moreover, carcinoma of the breast that developed before the age of 40 was significantly more common in Saudi women compared with patients in the United States (Elkum et al., 2007). This difference in the early onset of the disease in Saudi females could be due to considerable molecular differences both genetic and epigenetic between the ethnic groups. Breast cancer in young patients is often associated with more aggressive disease and poorer prognosis (Anders et al., 2008). One of the biological markers of interest in breast cancer is the matrix metalloproteinases (MMPs). Metastasis of breast carcinoma cells depends on some important factors such as proteolysis, cellular attachment, angiogenesis, migration through the barrier into secondary sites and colonization and proliferation in distant organs (Liotta \& Kohn, 1990). Proteolytic degradation of the basement membrane is a fundamental aspect of cancer development and a key event in the regulation of tumor proliferation and metastasis (Schwartz, 1996). Matrix degradation in the basement membrane is closely related to activities of various subtypes of MMPs and corresponding tissue inhibitors of matrix metalloproteinase, TIMP (Shim, 2007; Zhang 2012). Genetic alterations in breast cancer are those that change the DNA sequence such as single nucleotide polymorphisms (SNPs), insertion-deletion mutations and rearrangements. These types of mutations typically alter the gene product by changing the amino acid sequence of the protein or by altering the quantity of the produced protein. The matrix metalloproteinases, MMPs, constitute a family of secreted and membrane-associated zinc-dependent endopeptidases that are capable of selectively degrading a wide spectrum of extracellular matrix and non-matrix proteins (Simon et al., 2001). The MMP family has expanded to include 23 zinc-dependent endopeptidases, many of which were first identified by their over-expression in tumor cells (Laurie et al., 2012). They can be categorized by substrate specificity to give collagenases, stromelysins, gelatinases and membrane type MMPs. The broad range of substrates conveys their pivotal role during both normal physiological processes such as embryonic development, bone remodeling, angiogenesis and nerve growth and pathological states as in arthritis, atherosclerosis, liver fibrosis and cancer (Woessner 1998). The MMP-2 (gelatinase A) has type IV collagenolytic activity and is constitutively expressed by most connective tissue cells including endothelial cells, osteoblasts, fibroblasts and myoblasts (Strongin et al., 1995). Numerous investigators have demonstrated that MMP-2 is one of the essential players in promoting tumor invasiveness and metastasis and the levels of MMP-2 expression can be correlated with tumor grade (Poulsom et al., 1992; Boag \& Young, 1994). The MMP2 gene is located on chromosome 16 at q13-21 and

e-mail: hsaeed1@KSU.EDU.SA; hesham25166@yahoo.com Abbreviations: MMP-2, matrix metalloproteinase-2; SNPs, single nucleotide polymorphisms; RTPCR, reverse transcription polymerase chain reaction; TIMP, tissue inhibitors for matrix metakkoproteinase 
spans 27049 bp with thirteen exons. There were 283 entries of SNPs for the MMP-2 gene in the public NCBI Single Nucleotide Polymorphism database (dbSNP; build 125:http://www.ncbi.nlm.nih.gov/SNP/) (Yihong et al., 2009). A SNP in the promoter region of the MMP-2 (the $\mathrm{C}^{-1306} \mathrm{~T} / \mathrm{rs} 243865$ ) which disrupts an Sp1-type promoter site (CCACC box) affects MMP-2 expression or activity and may predispose to disease conditions, especially in those individuals carrying the MMP-2 variants associated with increased MMP-2 concentrations (Flavia et al., 2013). However, there are no reports about the association between MMP-2 C--1306 T gene SNP and breast cancer in Saudi population. In this study, we investigated whether this MMP-2 genetic polymorphism was associated with susceptibility to breast cancer in the Saudi population.

\section{MATERIALS AND METHODS}

Chemicals. All chemicals used were of analytical reagent, molecular biology, or chromatographic grade as appropriate. Water was deionized and distilled.

Samples collection. This study was conducted after review and approval of the Institutional Review Board of the Ethics Committee at King Khalid University Hospital in Riyadh, Kingdom of Saudi Arabia. Blood samples were collected from 90 confirmed breast cancer patients (age range, 33-77 years; mean age, 49 years) and 92 agematched healthy controls. The diagnosis of cancer was based on standard clinical, endoscopic, radiological, and histological criteria. Clinical and demographic characteristics were recorded, including age at diagnosis, estrogen receptor, progesterone receptor, HER status, family history, smoking habits, disease behavior, disease location, and need for surgery.

Genomic DNA isolation and purification. Genomic DNA was isolated from whole blood samples using QIAamp $^{R}$ DNA Blood Min Kit Cat. No. 51106 (Qiagen) according to manufacturer's instructions. Concentrations and purity of DNA samples were assessed using NanoDrop 8000 (Thermo Scientific).

Genotyping for MMP-2. Genotyping for the $\mathrm{C}^{-1306} \mathrm{~T}$ (rs 243865) in the 5'-flanking region of MMP-2 gene was performed by real time polymerase chain reaction (RTPCR) using TaqMan Allele Discrimination assay (Applied Biosystems, Carlsbad, CA, USA). Probes and primers used for the $\mathrm{C}^{-1306} \mathrm{~T}$ genotyping assay were customized as follows: forward 5'-GCCATTGTCAATGTTCCCTAAAACA-3'; reverse 5'-TGACTTCTGAGCTGAGACCTGAA-3' and probes 5'-CAGCACTC[T/C] ACCTCT-3'. TaqMan PCR was performed in a total volume of $20 \mu \mathrm{l}$ containing $20 \mathrm{ng}$ of genomic DNA, 1x
TaqMan master mix and $1 \mathrm{x}$ assay mix placed in 96-well PCR plate. Fluorescence from PCR amplification was detected using Chromo 4 detector (Applied Biosystems 7500 Fat Real Time PCR System) and analyzed with the manufacturer's software.

PCR and sequencing. PCR was carried out in a final volume of $50 \mu \mathrm{l}$ containing $25 \mu \mathrm{l}$ high fidelity PCR master mix (GE Healthcare, USA), $3 \mu$ of genomic DNA (50 ng) and $3 \mu \mathrm{l}$ (30 pmole) of each primer (MMP-2 forward 5'-CTGACCCCCAGTCCTATCTGCC-3'; reverse 5'-TGT'TGGGAACGCCTGACT'TCA-3'). The PCR conditions were 1 cycle at $95^{\circ} \mathrm{C}$ for $5 \mathrm{~min}$ followed by 30 cycles at $95^{\circ} \mathrm{C}$ for 40 seconds, $54^{\circ} \mathrm{C}$ for 40 seconds, and $68^{\circ} \mathrm{C}$ for $1 \mathrm{~min}$. The final extension step was carried out at $72^{\circ} \mathrm{C}$ for $5 \mathrm{~min}$. The PCR products were analyzed using $2.0 \%$ agarose gel stained with $0.5 \mu \mathrm{g} / \mathrm{mL}$ ethidium bromide and visualized using an ultraviolet transilluminator. Sequencing of the PCR products was carried out according to Sanger et al., (1977) using the MegaBACE 1000 DNA Sequencing System (Pharmacia/Amersham Co.). The chain termination sequencing reaction was conducted utilizing the DYEnamic ET terminator kit as an integral part of the MegaBACE 1000 DNA sequencing system. The sequencing reaction products were purified using DyeEx 2.0 Spin Kit (63206 Qiagen) and applied to MegaBace 1000 Sequencing machine.

Statistical analysis. Fisher's exact test and the odds ratio (OD) with 95\% confidence interval (CI) were used to test the association between cancer and the studied genetic polymorphisms and to describe the strength of the association. The associations were considered to be statistically significant if the Fisher's exact $p$-value was less than 0.05 and if the $95 \%$ CI excluded the value 1.0. All statistical calculations were done using MedCalc Software (Version 11.3.1.0 2010 MedCalc Software bvba).

\section{RESULTS}

\section{Characteristic of breast cancer patients}

The clinical characteristics of the studied breast cancer patients are summarized in Table 1 . The median age of the 90 patients was 49 years. Among a total of 90 breast cancer samples, 54 were staged as early disease (10 patients at Stage 0,1 patient at Stage I and 43 patients at Stage II), 34 patients (37.7\%) as locally advanced disease (Stage III) and 2 patients $(2.2 \%)$ had metastatic disease (Stage IV) at the time of diagnosis.

\section{Genotyping for MMP-2 C-1306T SNP}

The identification of MMP-2 $\mathrm{C}^{-1306} \mathrm{~T}$ polymorphism was carried out by two different PCR based methods. The first method was the amplification of 296 bp DNA fragment of the MMP-2 promoter followed by sequencing (Figs. 1 and 2). The second method was the TaqMan Allele Discrimination Assay utilizing primers and probes that identify both $\mathrm{C}$ and $\mathrm{T}$ alleles. The MMP-2 genotype distribution for cases and controls are shown in Table 2. In the present study there was a significant difference in the dis-
Estrogen receptor status (ER+/ER-) 47/43

Progesteronereceptor status (PR+/PR) 4 4/41

$\begin{array}{ll}\text { Progesterone receptor status (PR+/PR-) } & 49 / 41 \\ \text { Human Epidermal Growth Factor receptor-2 (HER+/HER-) } & 38 / 52\end{array}$
$0(11.11 \%)$

$1(1.111 \%)$

$34(37.7 \%)$

$2(2.2 \%)$ 


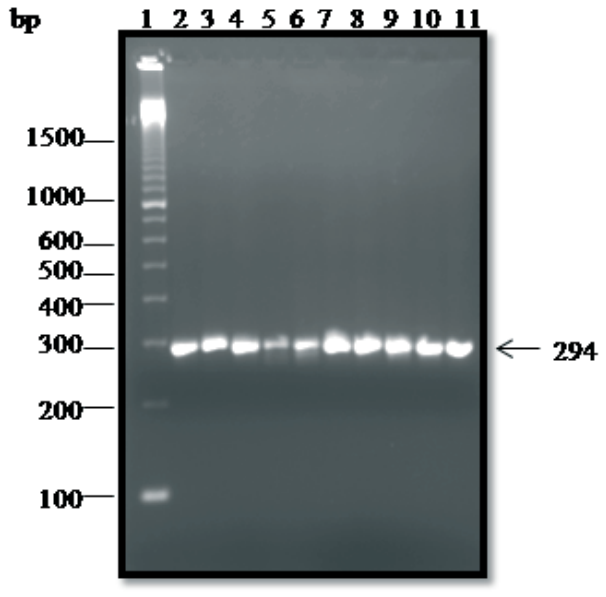

Figure 1. Agarose gel (2.0\%) electrophoresis for PCR products of MMP-2 promoter (Lanes 2-11).

Lane 1 represents 100 bp DNA molecular weight markers.

tribution of MMP-2 C/C genotype between breast cancer cases and the matched healthy control samples (Table 2). The frequencies of CC, CT and T'T genotypes in breast cancer cases were $58(0.65), 30(0.33)$ and 2 (0.02), respectively, whereas, for the healthy controls the frequencies were $73(0.79), 19(0.21)$ and 0 respectively. The homozygous CC $\left(\mathrm{OR}=2.022, \chi^{2}=5.36, p=0.02\right)$ and heterozygous CT $\left(\mathrm{OR}=1.98, \chi^{2}=4.1, p=0.04288\right)$ in breast cancer patients show higher risk when compared to healthy individuals (Table 2). Moreover, a significantly increased risk was also observed in women when $\mathrm{C} / \mathrm{T}+$ $\mathrm{T} / \mathrm{T}$ were combined together as compared with healthy women $\left(\mathrm{OR}=2.1, \chi^{2}=5.01, p=0.02\right)$. The correlation of MMP-2 polymorphic status with the clinicopathological characteristics was analyzed. Stratification of patients by age groups indicated that MMP-2 $\mathrm{C}^{1306} \mathrm{~T}$ SNP had a stronger association in above 48 years old patients than in patients younger than 48 years. Our results indicated that patients older than 48 years age with the homozygous variant (CC) genotype had an increased risk of breast cancer $\left(\mathrm{OR}=2.35, \chi^{2}=4.26, p=0.038\right)$ (Table 3). No significant association was observed between the HER, ER, and PR status and the genotypes under investigation in breast cancer patients and healthy individuals.

\section{DISCUSSION}

The human matrix metalloproteinase- 2 possesses proteolytic activity against type IV collagen, a major constituent of the basement membrane, and is therefore implicated in an extensive array of pathologies including atherogenesis, arthritis and tumor growth and metastasis (Clifford et al., 1984; Itoh et al., 1998; Yrjö et al., 1999;
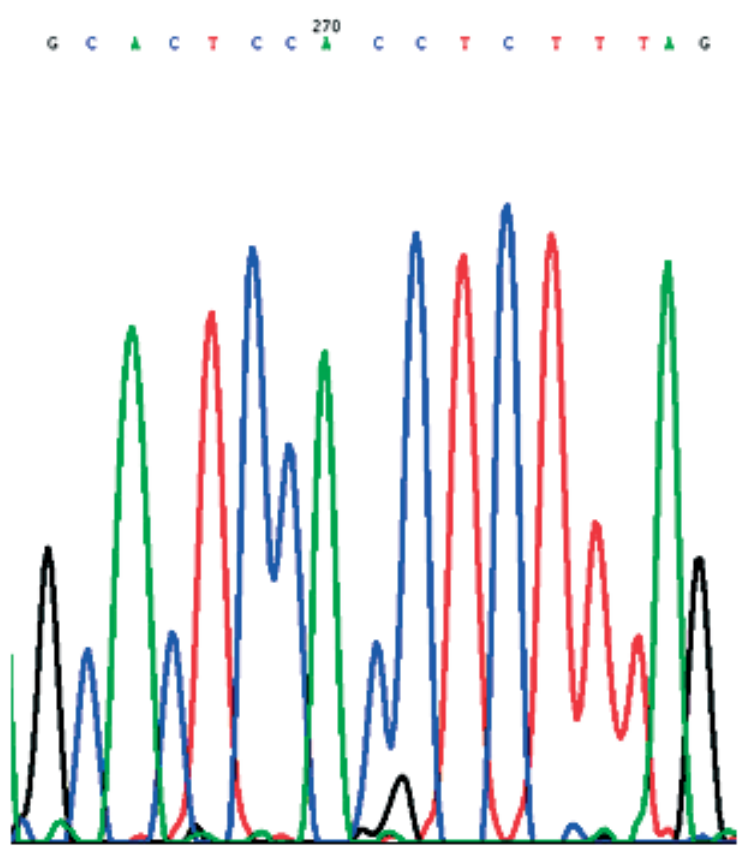

Figure 2. Sequence analysis of MMP-2 gene promoter shows homozygous genotype $(\mathrm{C} / \mathrm{C})$ and $C C A C C$ box.

Fang et al., 2000). Thus, any naturally occurring genetic variants that directly affect gene expression, and/or protein function would be expected to impact on progression of pathological processes involving tissue remodeling. Recently, a number of function altering polymorphisms have been found in the promoter of MMP-2. Some of these polymorphisms have allele-specific effects on the regulation of MMP-2 gene transcription and are associated with the development and progression of several diseases including breast cancer (Grieu et al., 2004), colorectal cancer (Enping, 2004) and prostate cancer (Priyanka et al., 2012).

In the present study, we investigated the role of MMP-2 $\mathrm{C}^{-1306} \mathrm{~T}$ polymorphism within the promoter site in breast cancer Saudi patients. Our results demonstrated a significant difference in MMP-2 allelic variant distribution with a 2.0 relative risk of breast cancer for $\mathrm{C} / \mathrm{C}$ and a 1.987 for $\mathrm{C} / \mathrm{T}$ heterozygous patients (Table 2) and this polymorphism may influence the invasiveness of breast cancer. These molecular epidemiological results are consistent with previous findings of Grieu et al., showing that, the $\mathrm{C}>\mathrm{T}$ transition at -1306 , disrupts the Sp1-type promoter site and results in a strikingly lower promoter activity with the $\mathrm{T}$ allele of the MMP-2 gene (Grieu et al., 2004). A study in Chinese population showed that the -1306 CC genotype doubles breast cancer risk (Zhou

Table 2. Distribution of MMP-2 C-1306T genotype and risk estimate

\begin{tabular}{lllllll}
\hline MMP2 Genotype & Cases & Controls & OR & $95 \% \mathrm{Cl}$ & $\mathrm{X}^{2}$ & $\mathrm{p}$-value \\
\hline $\mathrm{CC}(\mathrm{wt} / \mathrm{wt})$ & $58(0.65)$ & $73(0.79)$ & 2.022 & $1.1-3.7$ & 5.36 & 0.02057 \\
\hdashline $\mathrm{CT}(\mathrm{wt} / \mathrm{mut})$ & $30(0.33)$ & $19(0.21)$ & 1.987 & $1.02-3.88$ & 4.10 & 0.04288 \\
\hline$\Pi$ (mut/mut) & $2(0.02)$ & 0 & 6.282 & $0.29-133$ & 2.47 & 0.116 \\
\hdashline $\mathrm{CT}+\mathrm{TT}$ & $32(0.35)$ & $19(0.21)$ & 2.120 & $1.09-4.11$ & 5.01 & 0.02520 \\
\hline
\end{tabular}

OR, odds ratio; $p$, Fisher's exact p; $\mathrm{Cl}$, confidence interval; wt, wild-type allele for investigated polymorphism; mut, mutant allele. The frequency of the allele is in brackets. 
Table 3. Association between MMP2 gene polymorphism and clinicopathologic characteristics

\begin{tabular}{|c|c|c|c|c|c|c|}
\hline \multirow{2}{*}{ Variables } & \multicolumn{2}{|l|}{ Cases } & \multirow{2}{*}{ OR } & \multirow{2}{*}{$95 \% \mathrm{Cl}$} & \multirow{2}{*}{$\mathrm{X}^{2}$} & \multirow{2}{*}{$p$-value } \\
\hline & Group I & Group II & & & & \\
\hline Age group & $>49=52$ & $\leq 49=38$ & & & & \\
\hline$C C ; n=58(0.645)$ & $29(0.56)$ & $29(0.76)$ & 2.35 & $1.02-5.39$ & 4.26 & 0.038 \\
\hline$C T ; n=30(0.333)$ & $21(0.40)$ & $9(0.24)$ & 2.333 & $0.91-5.94$ & 3.22 & 0.07258 \\
\hline$T ; n=2(0.022)$ & $2(0.04)$ & 0 & 5.000 & $0.23-108.6$ & 1.94 & 0.16416 \\
\hline $\mathrm{CT}+\mathrm{TT} ; \mathrm{n}=32()$ & $23(0.44)$ & $9(0.24)$ & 2.556 & $1.012-6.456$ & 4.05 & 0.04430 \\
\hline ER Status & ER Positive (47) & ER Negative (43) & & & & \\
\hline$C C ; n=58(0.644)$ & $30(0.64)$ & $28(0.65)$ & 0.965 & $0.457-2.038$ & 0.01 & 0.92575 \\
\hline$C T ; n=30 \quad(0.333)$ & $16(0.34)$ & $14(0.33)$ & 0.938 & $0.388-2.267$ & 0.02 & 0.88609 \\
\hline$\pi ; n=2(0.023)$ & $1(0.02)$ & $1(0.02)$ & 1.071 & 0.064-17.96 & 0.00 & 0.96174 \\
\hline$C T+T ; n=32(0.356)$ & $17(0.36)$ & $15(0.35)$ & 0.945 & $0.398-2.244$ & 0.02 & 0.89866 \\
\hline PR Status & PR Positive (49) & PR Negative (41) & & & & \\
\hline$C C ; n=58(0.645)$ & $33(0.674)$ & $25(0.610)$ & 0.802 & $0.380-1.694$ & 0.33 & 0.56341 \\
\hline$C T ; n=30(0.333)$ & $15(0.306)$ & $15(0.366)$ & 0.758 & $0.313-1.835$ & 0.38 & 0.53797 \\
\hline$\pi ; n=2(0.022)$ & $1(0.02)$ & $1(0.024)$ & 0.758 & $0.045-12.71$ & 0.04 & 0.84656 \\
\hline $\mathrm{CT}+\mathrm{TT} ; \mathrm{n}=32()$ & $16(0.326)$ & $16(0.39)$ & 0.758 & $0.319-1.801$ & 0.40 & 0.52944 \\
\hline
\end{tabular}

OR, odds ratio; $\mathrm{p}$, Fisher's exact $\mathrm{p} ; \mathrm{Cl}$, confidence interval. The frequency of the allele is in brackets.

et al., 2004). In contrast, Roehe et al., (2007) reported, no association between $-1306 \mathrm{C}>\mathrm{T}$ polymorphism and breast cancer. Studies in a Swedish population found, no association between the MMP-2 promoter polymorphisms and colorectal cancer (Elander et al., 2006). Xu et al. (2004) investigated the role of the $-1306 \mathrm{C}>\mathrm{T}$ polymorphism within the MMP-2 gene promoter in colorectal cancer in the Chinese population and found that $\mathrm{C} / \mathrm{C}$ homozygotes were significantly more common among cancer patients. Our study showed that, the MMP-2C${ }^{1306} \mathrm{~T}$ SNP had a stronger association in patients older than 48 years than those under 48 years of age indicating that patients above 48 years with the homozygous variant CC genotype had an increased risk of breast cancer $\left(\mathrm{OR}=2.35, \chi^{2}=4.26, p=0.038\right)$ (Table 3).

Breast cancer is an epithelial tumor with high invasive and metastatic potential. Tumor growth, invasion and metastasis is a multistep process that is facilitated by the proteolytic degradation of the extracellular matrix and basement membrane (Zhang et al., 2012). The role of MMPs in this process has been firmly established based on numerous previously published studies (Azzam et al., 1993; Talvensaari-Mattil et al., 1998; Nagase \& Woessner Jr, 1999; Duffy et al., 2000). Because of its ability to degrade the basement membrane, MMP-2 has been postulated to be a potential marker of tumor progression and prognosis (Zhang et al., 2012). The MMP-2 promoter a $1.9 \mathrm{kbp}$ in size and contains Sp1 a ubiquitously expressed transcription factor that binds to GC/GT-rich elements and regulates a variety of genes in a constitutive or inducible manner (Rutter et al., 1998; Simon et al., 2001). One such motif, the CCACC box, has been shown to be essential for Sp1 binding and promoter function in several genes (Alory et al., 1999; Maouche et al., 1995). Sp1 is a multifunctional protein that can directly interact with the basal transcriptional complex as shown for the MMP-2 proximal promoter (Qin et al., 1999; Price et al., 2001), or alternatively function as a more general transcription factor and play an important role in directing tissue-specific expression (Block et al., 1996; Margana \& Boggaram, 1997). Clearly, any variant that abolishes Sp1 binding, such as the MMP-2 $\mathrm{C}^{-1306} \mathrm{~T}$ polymorphism, has the potential to affect the level and specificity of gene transcription.

In conclusion this study indicated that the MMP-2 $\mathrm{C}^{-1306} \mathrm{~T}$ polymorphism will be informative in tests of associations for breast cancer. In addition, this is the first study to demonstrated that MMP-2 C-1306 $\mathrm{T}$ polymorphism may be associated with the risk of developing breast cancer in a Saudi population.

\section{Acknowledgments}

The authors extend their appreciation to the Deanship of Scientific Research at King Saud University for funding the work through the research group project number RGP-VPP-309.

\section{Conflict of interest}

The authors declare that there is no conflict of interest for this article and there is no financial employment, consultancies, honoraria, stock ownership or options, expert testimony, grants or patents received or pending, royalties related to this manuscript.

\section{REFERENCES}

Alory I, Soussan L, Seger R, Yarden Y (1999) Neu differentiation factor stimulates phosphorylation and activation of the Sp1 transcription factor. Mol Cell Biol 19: 1961-1972.

Anders CK, Hsu DS, Broadwater G, Acharya CR, Foekens JA, Zhang Y, Wang Y, Marcom PK, Marks JR, Febbo PG, Nevins JR, Potti A, Blackwell KL (2008) Young age at diagnosis correlates with worse prognosis and defines a subset of breast cancers with shared patterns of gene expression. J Clin Oncol 26: 3324-3330.

Azzam HS, Arand G, Lippman ME, Thompson EW (1993) Association of MMP-2 activation potential with metastatic progression in human breast cancer cell lines independent of MMP-2 production. $J$ Natl Cancer Inst 85: 1758-1764. 
Block KL, Shou Y, Poncz M (1996) An Ets/Sp1 interaction in the 5 '-flanking region of the megakaryocyte-specific alpha IIb gene appears to stabilize Sp1 binding and is essential for expression of this TATA-less gene. Blood 88: 2071-2080.

Boag AH, Young ID (1994) Increased expression of the 72-kd type IV collagenase in prostatic adenocarcinoma. Demonstration by immunohistochemistry and in situ hybridization. Am J Pathol 144: 585-591.

Clifford A, Beeuwkes R, Lainey L, Silverman KJ (1984) Hypothesis: Vasa Vasorum and neovascularization of human coronary arteries, a possible role in the pathophysiology of atherosclerosis. $N$ Engl J Med 310: 175-177.

Cheema B, Gaul CA, Lane K, Fiatarone Singh MA (2008) Progressive resistance training in breast cancer: a systematic review of clinical trials. Breast Cancer Res Treat 109: 9-26.

Duffy MJ, Maguire TM, Hill A, McDermott E, Higgins O’N (2000) Metalloproteinases: role in breast carcinogenesis, invasion and metastasis. Breast Cancer Res 2: 252-257.

Elander N, Soderkvist P, Fransen K (2006) Matrix metalloproteinase (MMP) $-1,-2,-3$ and -9 promoter polymorphisms in colorectal cancer. Anticancer Res 26: 791-795.

Elkum N, Dermime S, Ajarim D, Al-Zahrani A, Alsayed A, Tulbah A, Al Malik O, Alshabanah M, Ezzat A, Al-Tweigeri T (2007) Being 40 or younger is an independent risk factor for relapse in operable breast cancer patients: the Saudi Arabia experience. BMC Cancer 5; 7: 222 .

Xu E, Lai M, Lu B, Xing X, Huang Q, Xia X (2004) A single nucleotide polymorphism in the matrix metalloproteinase-2 promoter is associated with colorectal cancer. Biochem Biophys Res Commun 324: 999-1003.

Fang J, Shing Y, Wiederschain D, Yan L, Butterfield C, Jackson G, Harper J, Tamvakopoulos, Moses MA (2000) Matrix metalloproteinase- 2 required for the switch to the angiogenic phenotype in a tumor model. Proc Natl Acad Sci USA 97: 3884-3889.

Flavia MG, Alisson MO, Riccardo L, Vanessa AB, Jose GS, Fabiola D, Jose ET (2013) Matrix metalloproteinase (MMP-2) gene polymorphisms affect circulating MMP-2 levels in patients with migraine with aura. Gene 512: 35-40.

Grieu F, Li WQ, Iacopetta B (2004) Genetic polymorphisms in the MMP-2 and MMP-9 genes and breast cancer phenotype. Breast Cancer Res Treat 88: 197-204.

Itoh T, Tanioka M, Yoshida H, Yoshioka T, Nishimoto H, Itohara S (1998) Reduced angiogenesis and tumor progression in gelatinase Adeficient mice. Cancer Res 58: 1048-1051.

Laurie AS, Sandra JT, William GS (2012) Matrix metalloproteinases: changing roles in tumor progression and metastasis. Am J Pathol 181: 1895-1899.

Liotta LA, Kohn E (1990) Cancer invasion and metastases. JAMA 263: $1123-1126$.

Maouche L, Lucien N, Cartron JP, Chretien S (1995) A CCACC motif mediates negative transcriptional regulation of the human erythropoietin receptor. Eur I Biochem 233: 793-799.

Margana RK, Boggaram V (1997) Functional analysis of surfactant protein B (SP-B) promoter:Sp1, Sp3, TTF-1, and HNF-3a transcription factors are necessary for lung cell-specific activation of SP-B gene transcription. I Biol Chem 272: 3083-3090.

Nagase H, Woessner Jr JF (1999) Matrix metalloproteinases. J Biol Chem 274: 21491-21494.

Poulsom R, Pignatelli M, Stetler-Stevenson WG, Liotta LA, Wright PA, Jeffery RE, Longcroft JM, Rogers L, Stamp GW (1992) Stromal expression of $72 \mathrm{kda}$ type IV collagenase (MMP-2) and TIMP-2 mRNAs in colorectal neoplasia. Am J Pathol 141: 389-396.

Price SJ, Greaves DR, Watkins H (2001) Identification of novel functional genetic variants in the human matrix metalloproteinase-2 gene: role of $\mathrm{Sp} 1$ in allele specific transcriptional regulation. J Biol Chem 276: 7549-7558.

Priyanka S, Tasleem AL, Rakesh K, Rama DM (2012) Association of promoter polymorphisms in MMP2 and TIMP2 with prostate cancer susceptibility in north India. Arch Med Res 43: 117-124.

Qin H, Sun Y, Benveniste EN (1999) The transcription factor Sp1, Sp3 and AP-2 are required for constitutive matrix metalloproteinase-2 gene expression in astroglioma cells. J Biol Chem 274: 29130 29137.

Rutter JL, Mitchell TI, Buttice G, Meyers J, Gusella JF, Ozelius LJ, Brinckerhoff CE (1998) A single nucleotide polymorphism in the matrix metalloproteinase-1 promoter creates an Ets binding site and augments transcription. Cancer Res 58: 5321-532.

Roehe AV, Frazzon AP, Agnes G, Damin AP, Hartman AA, Graudenz MS (2007) Detection of polymorphisms in the promoter of matrix metalloproteinase 2 and 9 genes in breast cancer in South Brazil: preliminary results. Breast Cancer Res Treat 102: 123-124.

Sanger F, Nicklen S, Coulson A (1977) DNA sequencing with chain terminating inhibitor. Proc Natl Acad Sci USA 74: 5463-5467.

Saudi National Cancer Registry (2011) Cancer incidence and Survival Report Sandi Arabia. 2007. Riyadh

Schwartz GK (1996) Invasion and metastases in gastric cancer: in vitro and in vivo models with clinical correlations. Semin Oncol 23: 316324.

Shim KN, Jung SA, Joo K (2007) Clinical significance of tissue levels of matrix metalloproteinases and tissue inhibitors of metalloproteinases in gastric cancer. J Gastroenterol 42: 120-128.

Simon JP, David RG, Hugh W (2001) Identification of novel, functional genetic variants in the Human matrix metalloproteinase-2 gene. J Biol Chem 276: 7549-7558.

Strnad M, Hrabak-Zerjavic V, Samija M (2007) Epidemiology, prevention and early detection of breast cancer. In Breast tumors. Samija M, Zuzbasic S, Separovic V, Vrdoljak VD, eds. 1st edn, p 27-32. Medicinska Naklada. Zagreb.

Strongin AY, Collier I, Bannikov G, Marmer BL, Grant GA, Goldberg GI (1995) Mechanism of cell surface activation of $72-\mathrm{kDa}$ type IV collagenase: isolation of the activated form of the membrane metalloprotease. J Biol Chem 270: 5331-5338.

Talvensaari-Mattila A, Paakko P, Hoyhtya M, Blanco-Sequeiros G, Turpeenniemi-Hujanen T (1998) Matrix metalloproteinase-2 immunoreactive protein: a marker of aggressiveness in breast carcinoma. Cancer 83: 1153-1162.

Tyczynski JE, Bary F, Parkin DM (2002) Breast cancer in Europe. ENCR Cancer Fact Sheets: 2

Woessner JF, Jr (1998). In Matrix metalloproteinases, Parks WC, Mecham RP, eds, pp 1-14, Academic Press, Inc., San Diego, CA.

Konttinen YT, Ainola M, Valleala H, Ma J, Ida H, Mandelin J, Kinne RW, Santavirta S, Sorsa T, López-Otín C, Takagi M (1999) Analysis of 16 different matrix metalloproteinases (MMP-1 to MMP-20) in the synovial membrane: different profiles in trauma and rheumatoid arthritis. Ann Rheum Dis 58: 691-697.

Hua Y, Song L, Wu N, Xie G, Lu X, Fan X, Meng X, Gu D, Yang Y (2009) Polymorphisms of MMP-2 gene are associated with systolic heart failure prognosis. Clin Chim Acta 404: 119-123.

Zhang M, Teng XD, Guo XX, Li ZG, Han JG, Yao L (2013) Expression of tissue levels of matrix metalloproteinases and their inhibitors in breast cancer. The Breast 22: 330-334.

Zhou Y, Yu C, Miao X, Tan W, Liang G, Xiong P, Sun T, Lin D (2004) Substantial reduction in risk of breast cancer associated with genetic polymorphisms in the promoters of the matrix metalloproteinase-2 and tissue inhibitors of the matrix metalloproteinase-2 genes. Carcinogenesis 25: 399-404. 